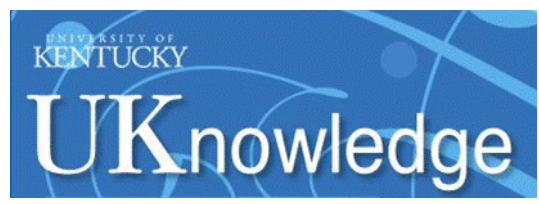

University of Kentucky

UKnowledge

\title{
The Role of Capillaries in the Lesser Ailments of Old Age and in Alzheimer's Disease and Vascular Dementia: The Potential of Pro- Therapeutic Angiogenesis
}

Charles T. Ambrose

University of Kentucky, cambros@uky.edu

Follow this and additional works at: https://uknowledge.uky.edu/microbio_facpub

Part of the Geriatrics Commons, Molecular Genetics Commons, and the Neurology Commons Right click to open a feedback form in a new tab to let us know how this document benefits you.

\section{Repository Citation}

Ambrose, Charles T., "The Role of Capillaries in the Lesser Ailments of Old Age and in Alzheimer's Disease and Vascular Dementia: The Potential of Pro-Therapeutic Angiogenesis" (2016). Microbiology, Immunology, and Molecular Genetics Faculty Publications. 112.

https://uknowledge.uky.edu/microbio_facpub/112

This Article is brought to you for free and open access by the Microbiology, Immunology, and Molecular Genetics at UKnowledge. It has been accepted for inclusion in Microbiology, Immunology, and Molecular Genetics Faculty Publications by an authorized administrator of UKnowledge. For more information, please contact UKnowledge@lsv.uky.edu. 


\section{The Role of Capillaries in the Lesser Ailments of Old Age and in Alzheimer's Disease and Vascular Dementia: The Potential of Pro-Therapeutic Angiogenesis}

Digital Object Identifier (DOI)

https://doi.org/10.3233/JAD-160303

Notes/Citation Information

Published in Journal of Alzheimer's Disease, v. 54, no. 1, p. 31-43.

(C) 2016 - IOS Press and the author

The copyright holders have granted the permission for posting the article here.

The document available for download is the author's post-peer-review final draft of the article. The final publication is available at IOS Press through https://doi.org/10.3233/JAD-160303. 


\title{
The Role of Capillaries in the Lesser Ailments of Old Age \\ (muscle weakness, minor memory lapses, \& cold intolerance) and in Alzheimer's Disease \& Vascular Dementia: the Potential of Pro-Therapeutic Angiogenesis
}

\begin{abstract}
... 164 words
Apart from chronic diseases (arthritis, diabetes, etc.), old age is generally characterized by three lesser ailments: muscle weakness, minor memory lapses, and cold intolerance. This trio of complaints may have a common, underlying cause -- namely, the age-associated reduced microcirculation in muscles, brain, skin, and elsewhere in the body. The Angiogenesis Hypothesis proposes that old age is in part a deficiency disease due to the decline in angiogenic (AG) factors, resulting in a reduced capillary density (CD) throughout the body. Over fifty published papers document waning levels of AG factors and/or decreased CD in various organ systems of aged animals and people -- including those with Alzheimer's disease. The deficiency of AG factors is analogous to that of certain hormones (e.g., testosterone) whose blood levels also decline with age. In theory, therapeutic angiogenesis employing recombinant AG factors is a tenable treatment for the lesser ailments of old age and may improve the later years of human life. An optimal administration route may be intranasal.
\end{abstract}

Keywords: aging, angiogenesis, capillary density, muscle weakness, memory lapses, cold intolerance, vascular dementia, $\mathrm{AD}$ 


\section{The Role of Capillaries in the Lesser Ailments of Old Age \\ (muscle weakness, minor memory lapses, \& cold intolerance) and in Alzheimer's Disease \& Vascular Dementia: the Potential of Pro-Therapeutic Angiogenesis}

\section{Introduction}

After years of relative good health, many long lived persons in their sixties or so begin experiencing a trio of lesser ailments common to old age. The most conspicuous one is muscle weakness and ready fatigue. More subtle are minor memory lapses, euphemistically termed 'senior moments'. The third ailment is cold intolerance, which is evident in older persons frequently feeling the need to 'bundle up to stay warm'. Constipation and occasional difficulty in swallowing are also complaints mentioned in the geriatric literature, but the three lesser ailments are more frequent complaints.

The trio may be linked together through an age-associated microvascular change discussed in several earlier papers for more serious conditions $[1,2]$. There, I summarized data from the literature suggesting that Alzheimer's disease (AD) and vascular dementia (VaD) are due in part to diminished capillaries in the brain. Others had advanced the same idea [3-9]. This histological change is usually expressed as a reduced 'capillary density' (CD) and was first studied extensively in rat brains by E. Horne Craigie in the 1920s [10]. In 2003, Riddle et al. reported that 14 of 21 studies on old people and old animals showed a reduced cerebral CD [11]. 
And in 2011, based on 37 reports, Brown and Thore concluded that "there is strong evidence of reduced vascular density" in the brains of aging animals and people, including those with AD and a mouse model of $\mathrm{AD}$ [12]. While several early studies reported 'increased' cerebral CD or 'no change' in CD with aging, the "preponderance of studies" showed reduced values [12]. Tissue shrinkage may account for the discordant CD values, as discussed elsewhere [2].

My several reviews concerning capillary density have related the reduced CD to the waning angiogenesis during aging [1,2]. By way of background, the capillary system emerges during embryonic and post-natal life via a process termed vasculogenesis, in which the original vessels are derived from endothelial stem cells under the influence of various angiogenic factors. Later, the microcirculation develops via angiogenesis, in which capillary branches bud from the early ones $[13,14]$. Additional angiogenesis occurs during the ovarian cycle and pregnancy. Local angiogenesis is vital for wound healing, other injuries involving hypoxia, and possibly capillary maintenance. But during the final phase of life, levels of angiogenic factors decline, resulting in the reduced CD throughout the body.

One aspect of the reduction in CD and AG not commonly appreciated is that it is a general phenomenon of aging -- occurring not only in the brain but in skeletal muscles, skin, larynx, colon, kidneys, lungs, and vasa vasorum. This extensive change has implications beyond $\mathrm{AD}$ and $\mathrm{VaD}$ which extend to aging -- the main concern of this essay.

Support for this general finding comes from over 50 published reports on aged people and old animals exhibiting reduced CD and diminished AG factors collectively in nine organ systems. CD and levels of AG factors from adults or mature animals have been paired with comparable values from the aged for the following summaries. Presenting data pairs is more persuasive than generalizing about reduced values. A reduction in CD is documented in 25 data pairs obtained from people and 22 from animals [2, Tables $2 \& 3 ; 15$, Tables $1 \& 2$ ]. Similarly, 
an age-associated decline in AG is demonstrated in 8 data pairs derived from animals and 10 from people [15, Tables $3 \& 4$; also Table 3 below]. These 65 data pairs come from various areas of the body.

The reduction of $\mathrm{CD}$ is not associated with any environmental influence but, again, is determined by angiogenic factors, whose levels throughout the body are genetically programmed from embryonic development on and change like hormones at different stages of life. Unlike hormones, AG factors are produced by various cell types throughout the body -- fibroblasts, mononuclear cells, platelets, muscles, tumor cells, etc. Three angiogenic factors commonly studied are vascular endothelial growth factor (VEGF), fibroblast growth factor (FGF), and angiogenin (Ang) -- all of which have been reviewed elsewhere [16,17].

Extensive data on $\mathrm{CD}$ and $\mathrm{AG}$ in the brain and muscles were presented in my earlier reviews $[1,2,15]$. Only representative data pairs from them are included in Tables $1 \& 2$ and the text of this essay in order to limit its length and avoid the charge of self-plagiarism [18]. Data pairs only recently found in reports on other organ systems are listed in Table 3 and discussed below. Later sections consider the significance of all these data for treatment of the lesser ailments of the aged and the more serious problems of cognition.

\section{Muscle weakness}

The waning muscle strength experienced by older persons generally reflects the loss of muscle mass (sarcopenia), which is due in part to decreased exercise but is a natural consequence of aging $[19,20]$. An underlying cause is a reduced microcirculation. Eighteen published reports showing reduced capillary density and declining angiogenic factors in the leg muscles of aged people and animals have been summarized elsewhere [15, Tables 1-4]. Data from only three such reports are listed in Table 1 and discussed immediately below. 
Capillary density. This has commonly been measured as the sum of capillary lengths per section of tissue $\left(\mathrm{mm} / \mathrm{mm}^{3}\right)$. Coggan et al. examined the CD of the lateral gastrocnemius muscles of young persons ( $24 \pm 1 \mathrm{yrs})$ and the old ( $64 \pm 1 \mathrm{yrs})$ and noted a reduction from $\mathbf{3 0 8} \pm 16$ in young males to $\mathbf{2 2 8} \pm 13$ in older men and from $\mathbf{3 3 8} \pm 19$ in young females to $\mathbf{2 4 8} \pm 12$ in older women [21]. Numerous other investigators have obtained similar data [22-24]

Reductions in CD have been recorded in the hind limbs of various aged animals: dogs, rabbits, rats, and mice [25-27]. Rivard and associates presented findings in several tables from which were derived the following data pairs: the av. values for capillaries $/ \mathrm{mm}^{3}$ in $6-8$ month old rabbits was $\mathbf{1 7 0}$ and for those 4-5 years old was $\mathbf{1 3 0}$ [28, Fig. 5G]. In mice the values were $\mathbf{7 1 0}$ at 12 weeks of age and $\mathbf{3 5 0}$ at 2 years [28, Fig. $5 \mathrm{H}]$.

Angiogenic factors. Again, capillary density in muscles is determined by the local levels of AG factors. Levels of vascular endothelial growth factor (VEGF), basic fibroblast growth factor (bFGF), and platelet derived growth factor (PDGF) have been measured in men and mice of different ages [men: 24,29-31; mice: 28,32-33]. For example, in studies on the vastus lateralis muscle, Ryan et al. found that at rest VEGF protein levels were $\mathbf{1 . 0 5}$ in young men (age 19-25 yrs.) but only $\mathbf{0 . 5 5}$ in old men (60-72 yrs.) [24]. Similarly, the 18s $m R N A$ VEGF level was $\mathbf{1 . 0}$ in the young men but only $\mathbf{0 . 4}$ in old men [24]. In muscles of mice, Wagatsuma et al. reported VEGF levels of $\mathbf{1 . 0}$ in the young ones (2.5 mo.) and only $\mathbf{0 . 7}$ in the old ( $22 \mathrm{mo}$.) [33]. Thus, in these examples and other studies, the values were consistently lower in the aged.

Exercise. Exercise elicits local angiogenesis around muscles and a transient increase in local capillary density. There are 21 reports documenting this response -- 15 in people and 6 in animals [15, Table 5]. In the study cited above, Ryan et al. found that four hours after exercise the values for VEGF $\underline{m R N A}$ rose to $\mathbf{3 . 4}$ in young men but only to $\mathbf{1 . 8}$ in old men [24]. After exercise, the levels of VEGF protein rose less in older men than in younger ones. Other 
investigators have found the same age-discrepancy in $\mathrm{CD} / \mathrm{AG}$ responses following exercise [34,35]. In any case, there now is a firm physiological basis for the 'morning constitutional' to help maintain lower body strength. Also any AG factors released into the circulation while walking might reach the brain and improve cerebral microcirculation and possibly cognition.

\section{Brain: Minor Memory Lapses ... capillary blood flow}

In older adults, forgetting momentarily a familiar word or name, which seems 'on the tip of the tongue', is defined as a 'retrieval block' [36]. A simple explanation here is that compared to youngsters, most elderly persons simply have a larger data base in their brain from having absorbed so much information over many decades of a long life. To be recalled, a particular word or name competes, so to speak, with billions of other memories residing somewhere among the billions of synapses. A particular book may be found quickly in a small library but takes longer in a large one. Or as one commentator wrote, "It's not that you're slow ... you know so much" [37]. Challenging this interpretation are those rare individuals diagnosed with a "highly superior autobiographical memory' (HSAM), who can recall in infinite detail the countless events experienced throughout their daily life [38]. There is no report of their having more frequent memory lapses.

The exact mechanism eliciting recall of a word or name remains a mystery but involves specific neurons whose synapses when 'fired'/engaged can evoke a particular memory in one's consciousness [36]. In $\mathrm{AD}$ and $\mathrm{VaD}$, the loss of various memories is believed due to the death or irreversible malfunction of key neurons, thus accounting for the absent synaptic responses. But in persons having 'a senior moment', the blocked word or name is generally recalled later, indicating that the relevant neurons are intact but their ability to induce synaptic responses is momentarily impaired. Theoretically, this could be due to a transient ischemia at the synaptic 
site responsible for a particular memory trace. But how could ischemia in the brain be limited to a tiny area and be transient?

Capillary Blood Flow. A controversial issue several decades ago concerned whether capillaries in the brain have a steady flow of blood at all times or whether some may have a variable, reduced flow sometimes. Kuschinsky \& Paulson concluded that all capillaries exhibit $100 \%$ flow at all times [39]. But other investigators have found reduced flow rates and varying values in different areas -- $84 \%$ by Collins et al., $70-80 \%$ by Kikano et al., and $50 \%$ by Weiss [40-42]. While different assay methods may account for the differing results, this uncertainty suggests that blood flow in individual capillaries may indeed vary. A transient, diminished local capillary blood flow and the resultant lowered glucose or oxygen supply might limit the excitation of the synapses involved in a particular memory and account for its momentary lapse or pause. But what might explain such a transient local change in the elderly?

Stress. Here I'm reminded of my own recent memory lapses at age 86. Over the past year or so, I've experienced them occasionally during lectures to medical students and also in serious or spirited conversations. These lapses are often masked by my using synonyms or some circumlocution. Just as my muscle strength and muscle reserve are now decidedly less than formerly, so too may be my 'cognitive reserve' $[2,43]$. Perhaps in an elderly person a slight emotional stress may divert the microcirculation momentarily and by chance from a specific area of memory recall to an area where blood flow is more critical -- e.g., to some other region of the brain or to the heart.

\section{Brain: Major Cognitive Deficiencies ... capillary density}

It's unknown whether the occasional memory pauses in older persons portend the more serious cognitive decline seen later in them. Different mechanisms seem probable. In contrast to 
the transient memory lapses, the mental deterioration seen in the aged is generally progressive and permanent and is believed due to neurons lost or impaired, resulting from cerebral vascular insufficiency. One cause of a permanently reduced cerebral blood flow (CBF) would be a reduced number of cerebral capillaries. Groups concerned with the overall/gross CBF (like Grossman et al.) have measured it with various imaging modalities or bolus fractional methods, but few of them have also assessed capillary cerebral blood flow, like Desjardins et al.[44,45].

Capillary density. Available in a previous publication are the data from 23 studies showing reduced numbers of capillaries in the aged: 5 reports in older persons, 5 reports in those with Alzheimer's disease, and 13 reports in aged rats and mice [2, Tables $2 \& 3]$. In this essay it will suffice to list in Table 2 representative CD data from three such reports on the brain. The six data pairs (young vs. old) are briefly discussed in the text below -- first those from people and then from rats.

Mann et al. compared the sum of capillary lengths/section $\left(\mathrm{mm} / \mathrm{mm}^{3}\right)$ in the frontal cortex and found the average CD there for six adults ages $\underline{26-58 \text { years }}$ to be $965.5 \pm 133$, while that for

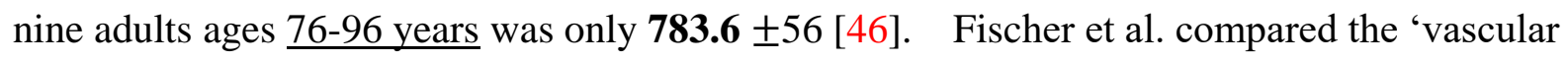
density index' in the brains of 6 persons aged 23-90 with that in 16 AD patients aged 76-92. These authors reported average values in the prefrontal cortex: 94.6 vs. 75.4, in the basal forebrain: $\mathbf{8 6 . 8}$ vs. $\mathbf{4 2 . 7}$, and in the hippocampus: $\mathbf{8 2 . 3}$ vs. $\mathbf{5 0 . 2}$ [47].

Likewise, Buchweitz-Milton and Weiss measured cerebral CD in adult rats (8-10

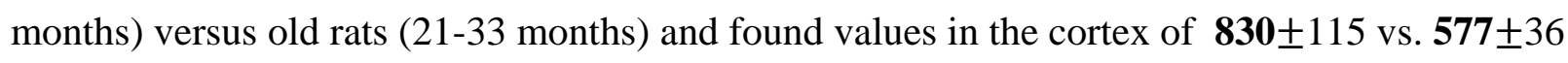
and in all six brain areas of $\mathbf{8 3 7} \pm 54$ vs. $\mathbf{5 9 2} \pm 22[48]$

Angiogenesis. So far as I am aware, there are no published data on levels of AG factors in the brains of aging persons, but there is one study in old animals. Vascular endothelial growth factor (VEGF) has been reported diminished in the parietal cortex of rats, declining from $\mathbf{3 2 . 2}$ 
$\mathrm{pg} / \mathrm{mg}$ protein in young rats to $\mathbf{2 2 . 5} \mathrm{pf} / \mathrm{mg}$ protein in old ones [49]. The reduced VEGF in the brains of old rats noted here and similar findings in human muscles reviewed in the preceding section suggest that a comparable reduction of AG factors in the human brain may be found when specifically looked for in persons with $\mathrm{VaD}$ and $\mathrm{AD}$.

\section{Skin: Cold Intolerance and reduced CD}

Elderly persons complain that they sometimes feel chilly all over or that their fingers and feet are cold to the touch. These conditions could be termed dysthermia or 'krymoesthesia' $($ krymo, Gr. = cold; esthesia, $\mathrm{Gr} .=$ feeling $)$. Internet web sites addressing this issue have invoked hypothyroidism or social isolation as causes. Review papers in the geriatric literature have focused on lower limb temperature fluctuations, thermal sensitivity/perception, or preferred room temperatures [50-52]. 'Cold feelings' in the elderly may be due to two conditions in the subcutaneous tissues: transient vasoconstriction of arterioles there and reduced local fat. Both conditions may be linked to a reduced microcirculation in the subcutaneous tissues, as explained later.

In a related vein, I haven't found a clear explanation in the literature of why during the spring and late fall in the northern US states that many older adults go about well bundled up with gloves and earmuffs, while young people walk around in shorts and light clothing. The contrast between ages may reflect youthful exhibitionism. But a physiological explanation for cold intolerance may involve the insulating function of subcutaneous adipose tissue.

Adipose tissue is located predominantly in two areas of the body -- under the skin as subcutaneous adipose (SA) and surrounding the viscera in the peritoneal cavity as visceral adipose (VA). Adipose tissue is the only adult tissue which can grow/increase and regress any time throughout adulthood [53]. It is highly vascularized and its level in either area is controlled 
by angiogenesis. SA shows greater CD and AG levels than VA [54]. Silha et al. reported increased levels of vascular endothelial growth factors in obese subjects [55].

Subcutaneous adipose may exert two functions in the body -- insulating it against the cold and cushioning/supporting the overlying skin. The former function may help explain cold intolerance of the aged, who have reduced SA. The latter function involves fat filling subcutaneous spaces and keeping the skin free of wrinkles. In old age when SA is lost, wrinkles invariably appear on the back of the hand, where engorged veins become conspicuous. But why and when might SA be lost?

Capillary density. In Table 3 are three reports of $\mathrm{CD}$ in the skin of mature and old persons. Helmbold et al. obtained biopsies from the trunk area and found CD in the upper dermal plexus of 4.3/hpf (high power field) for those 30-49 years of age and 1.4/hpf for persons over 70 years of age [56]. Vybohova et al. measured the percent capillary area in papillary dermis from the anterior thoracic region of cadavers and reported values of $\mathbf{1 . 4 2 \%}$ for subjects age 31-51 and $\mathbf{0 . 6 3 \%}$ for those 71-80 years [57]. And in the ears of hairless rats, Vollmar et al. found values for the cutaneous capillary density of $77.6 \mathrm{~cm} / \mathrm{cm}^{2}$ for 30 weeks old rats versus $37.5 \mathrm{~cm} / \mathrm{cm}^{2}$ for 78 week old ones -- a $40 \%$ reduction [58].

In summary, the reduced $\mathrm{CD}$ in the skin of old persons presumably reflects a decreased level of angiogensis, which in turn would account for their diminished subcutaneous adipose, cold intolerance, and a conspicuous sign of aging -- skin wrinkles.

\section{Other Areas with Reduced CD and Diminished AG}

Organ systems other than the brain, leg muscles, and skin also show functional declines with age in parallel with a reduced $\mathrm{CD}$ and/or lower levels of $\mathrm{AG}$ factors. 
Larynx. Dysphagia could be considered the fourth 'lesser ailment of the elderly', since difficulty in swallowing (notably large pills) occurs in $15 \%$ to $40 \%$ of those over 60 years of age [59]. Dysphagia is thought due to sarcopenia. Russell et al. reported a reduced capillary density in the thyroarytenoid muscles of old rats (28-30 mo.) compared with adult ones (9 mo.): declining from $\mathbf{1 7 . 0}$ to $\mathbf{9 . 3 5}$ [60]. A resulting loss of laryngeal muscle mass could affect both phonation and deglutition.

Colon. The taenia coli are three longitudinal ribbons of smooth muscles on the outside of the colon whose contractions stimulate gut motility and tone. Gabella reported a substantial fall in the 'capillary profile' in the colon of aged guinea pigs compared to young one -- a reduction from 9 capillary/10,000 $\mu \mathrm{m}^{2}$ in young adults to "less than $\mathbf{5}$ in the aged animal" [61]. A common complaint of elderly people is constipation [62]. If a similarly reduced CD occurs in the colon of older people, perhaps this could contribute to their costive bowel problems.

Kidney. Three studies involving old mice and old rats show reduced capillaries in the cortex and medulla of the kidney, as summarized here in Table 3 [63-65]. For example, Kang et al. found an age-associated reduced "capillary staining" in the peritubular area of the rat kidney: $\mathbf{3 9 . 3 \%}$ in 3-month old rats and $\mathbf{1 9 . 2 \%}$ in 24 -month old rats. They also noted decreased VEGF expression in the kidney medulla of aging rats: $\mathbf{1 1 . 3 \%}$ (3 mo.) and only $\mathbf{5 . 4 \%}$ (24 mo.) [65]. These authors wrote that the peritubular capillary loss and the declining VEGF expression "strongly correlate with the degree of glomerulosclerosis" and other pathology in rat kidneys.

Lung. Older persons show an age-related reduction in the diffusion capacity of their lungs, which reflects in part a reduction in the "lung blood capillaries" [66]. Alveolar-capillary clearance rates (\% per minute) were measured by Braga et al. in the three age groups: <30, 3135, >56 yrs [66]. They found a progressive decline of $\mathbf{1 . 3 8 \%} \rightarrow \mathbf{1 . 0 8 \%} \rightarrow \mathbf{0 . 7 6 \%}$, respectively. In 1959 McGrath and Thompson measured the diffusing capacity for carbon 
monoxide ( $\mathrm{D}_{\mathrm{CO}}$ ) in the lungs of three groups of normal men -- ages 17-36, 38-58, and 60-75 [67]. To take into account differing lung size, I calculated an adjusted value for lung capillaries by dividing the average Dco of each group by each one's respective average vital capacity. This yielded an age-linked declining set of values -- $\mathbf{0 . 8 6} \rightarrow \mathbf{0 . 7 3} \rightarrow \mathbf{0 . 5 1}$ for the above three age groups.

Vasa vasorum. This is a network of capillaries supplying the walls of large blood vessels, such as the aorta and vena cava. Phillips et al. reported that these capillaries in the rat femoral artery "were dramatically reduced in number by 12 months, and even fewer were present at 24 months" [68]. The authors speculated that this reduced CD in arteries in people "may explain why the aged are more prone to atherosclerosis."

Peripheral blood mononuclear cells. Solerte et al. determined the level of VEGF in peripheral blood mononuclear cells from three groups: healthy young adults (average age, 32.2 years), old subjects (77 years), and persons with $\mathrm{AD}$ (76.5 years). The values were, respectively, $296 \mathrm{pg} / \mathrm{ml}, \mathbf{1 3 7} \mathrm{pg} / \mathrm{ml}$, and $125 \mathrm{pg} / \mathrm{ml}$ [69]. This study concerned the role of immune cells in AD and produced the above data, which, parenthetically, is applicable to the thesis of this essay.

Liver. Age-linked changes in capillaries may likely be found in other organ systems when examined for them, as suggested earlier. One such example is 'pseudocapsillarization' in the liver of aged people and animals [70-72]. Here the liver sinusoidal endothelial cells are thickened and show reduced fenestration (porosity). These changes likely contribute to ageassociated hepatic impairment and may be related to the reduced CD seen elsewhere in the aged.

\section{The Angiogenesis Hypothesis: Correlation vs. Causation}

The above data from nine organ systems underlie the Angiogenesis Hypothesis of Aging. It proposes that a reduced angiogenesis throughout the body accounts in part for the lesser 
ailments of early old age and for the more serious cognitive deficits in later life. A central issue in the hypothesis is whether the reduced capillary density (reduced microcirculation) causes these hallmarks of aging or whether the reduced CD is coincidental [73]. Several of the five reports noted below provide support for the hypothesis, while others suggest studies to determine its validity.

1) Physiological aging in people is evident by numerous signs and symptoms -- e.g., wrinkles in the skin, the LAs, and dementias. The development of these hallmarks of aging varies from person to person, reflecting genetic backgrounds and life habits. A reduced CD at some one point in time and the presence then of some physical sign of aging does not establish that the former caused the latter. However, if the progressive decline in CD over time parallels the gradual emergence of some hallmark of aging in an individual or group, then the case for cause-and-effect would be stronger. Degens et al. measured $\mathrm{CD} / \mathrm{mm}^{2}$ and the fiber number in the plantaris muscle of rats of age 5 mo., 13 mo. and 25 mo. The CD values fell progressively: with age: $1000 \rightarrow 850 \rightarrow 700$, while the fiber number (muscle mass) decreased between months 13 and 25 [26, ex. Fig. 4].

2) Most reports which have compared CD or AG in the young and old have determined values at only two dates and in two different populations. But a study by Frontera et al. measured muscle strength in a cohort of 8 men over a 12 year period. The cohort exhibited a $28.5 \%$ decline in $60^{\circ}$ knee flexion of the vastus lateralis muscle over 12 years and a $20.3 \%$ reduction in the muscle's capillary density -- from $\mathbf{1 . 3 9}$ to $\mathbf{1 . 0 8}$ [19]. Unfortunately, the men were not tested at intervals to provide intermediate data points for a hypothetical graph relating CD with degrees of flexion.

3) Support for the AG hypothesis might come from retrospective CD measurements in brain collections like that of the Nun Study, created by David Snowdon and continued over 
several decades [74]. Six hundred nuns were enlisted and assessed during their later years for their cognitive status. Over 500 brains from this cohort are available for histological study. Whether a reduced cerebral CD correlates with cognitive decline could be determined by comparing $\mathrm{CD}$ in the brains of two groups of nuns: those who remained cognitive normal throughout old age and those who showed evidence of dementia.

4) A different approach for establishing cause and effect would be to administer a naturally occurring regulatory factor which declines during old age (e.g., VEGF, etc.) and to show that this treatment improves some feature of aging or arrests its natural development. For example, Wang et al. found that exogenous VEGF improved the cognitive function of transgenic AD mice [75]. Morris water maze tests showed that mice given daily intraperitoneal injections of VEGF for three day subsequently exhibited improved learning and memory. Blood vessels also increased in the hippocampus but gradually declined after the second week.

5) In a remarkable study involving angiogenesis and cognition, Harry S. Goldsmith exploited a rich natural source of AG factors -- the omentum, which cushions the abdominal viscera. An omental pedicle was surgically transpositioned under the skin and stretched to reach and cover part of the brain surface in each of $25 \mathrm{AD}$ patients. Ten showed slight cognitive improvement, while "nine demonstrated marked cognitive increases," presumably as a result of the pedicles supplying AG factors to the brain and improving the cerebral microcirculation [76].

The practical import of the angiogenesis hypothesis is its corollary that treatment of the aged with recombinant AG factors (= therapeutic angiogenesis) might reverse the age-linked decline in $\mathrm{AG}$ and $\mathrm{CD}$, relieve the lesser ailments of old age, and delay/reduce later cognitive changes.

\section{Theories of Aging and Anti-aging Therapies}


A general science writer once concluded that there seems to be a theory on aging for every published investigator [77]. Gerontologists have previously ascribed the physical and mental decline of old age to the various causes listed in Table 4 [78-83]. The hypothesis presented in this essay is a new addition to that list. As noted in the introduction, numerous groups have proposed a vascular deficiency in the brain for Alzheimer's disease and other senile dementias. However, so far as I am aware, no group has invoked a reduced CD throughout the body in many organ systems to account for the general signs and symptoms of aging -including the lesser ailments, the dementias, and declining organ functions. This essay proposes that a declining angiogenesis throughout the body contributes significantly to aging but allows that other influences may also exist. Even if aging is a multifactorial process, relieving one of the cumulative causes by therapeutic angiogenesis would have a beneficial effect on the elderly.

The numerous theories of aging outlined in Table 4 can be considered under two broad causes: stochastic (random) versus developmental (genetic). They range from the obvious dangers of daily life (diseases, stress, toxins, et al.) to the modern biological discoveries (somatic mutations, telomere shortening, stem cell loss, et al.).

Anti-aging Therapies. Many theories of aging seem scientifically plausible but suggest no feasible means of relieving the signs and symptoms of the aged -- or at least by any measure currently available for general use. Examples are those notions invoking a biological clock, chemical cross linking, defective transcription, etc. On the other hand, some ideas infer the use of available natural agents to treat medical condition of the aged. For example, one theory suggested that cholinesterase inhibitors (ChEIs) might ameliorate cognitive decline of old age, but clinical trials with these agents have been disappointing [84-87]. Another theory postulated that oxidative stress due to oxygen free radicals accumulating in the tissues accelerates aging. 
But treatments with various antioxidants (Ginkgo biloba, teas, flavonoids, vitamin E, etc.) have yielded conflicting results [88]. Anti-aging studies have also considered hormonal deficiencies.

Correcting Deficiency States. The loss of muscle strength during old age has been associated with decreasing levels of growth hormone and various sex hormones. But the administration of these agents has "not been uniformly proven to be safe and of benefit" [89]. Parenthetically, there is evidence that "androgens regulate angiogenesis" [90]. For example, dihydrotestosterone induces VEGF secretion from fibroblasts of young men but not from those of older men ]90]. An age-linked declining level of testosterone or other hormones may have a secondary influence on AG. However, therapeutic angiogenesis with recombinant AG growth factors seems a more direct treatment of the AG deficiency of old age.

\section{Pro-Therapeutic Angiogenesis}

Therapies involving capillaries have employed opposite approaches in exploiting angiogenesis -- anti-AG and pro-AG. Anti-angiogenesis has been pursued for correcting those conditions where AG has had a harmful effect -- e.g., promoting growth of tumors or diabetic retinopathy. Anti-angiogenesis trials have sought to suppress the action of a single factor -- e.g., VEGF with bevacizumab, an anti-VEGF antibody [91].

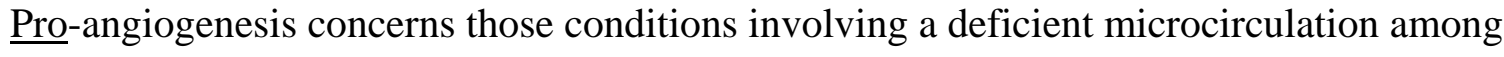
other circulatory problems -- e.g., cardiac insufficiency, intermittent claudication, cerebral infarcts, diabetic ischemia, etc. Included here could also be the lesser ailments of old age. The therapeutic potential of pro-angiogenesis has been widely acknowledged for some time. In a 2011 paper, Peter Carmeliet and Rakesh Jain wrote, "The revascularization of ischaemic tissues would benefit millions, but therapeutic angiogenesis remains an unmet medical need" [92]. Other investigators have reached the same conclusion [93-96]. Pro-AG would seem more 
complicated than anti-AG, since the former is believed to involve the coordinated action of several factors.

Heinl-Green et al. suggested using a 'master switch' for the AG cascade, such as hypoxia inducible factor (HIF), which is now available in a recombinant form [97]. Because HIF-1 $\alpha$ is rapidly degraded in the body, it was presented as a plasmid or encoded by adenovirus (Ad2) for administration to experimental animals. The latter (Ad2HIV) has produced transient revascularization in a porcine model of chronic myocardial ischemia [97]. A clinical trial using Ad2HIV-1a/VP16 was undertaken in patients with intermittent claudication [98]. Clinical trials have also sought to define the role of HIF-1 in cancer progression [99,100]. The long term outcomes of these studies may have some relevance to easing the downward course of aging.

Selecting the correct AG factor/s for administration in human studies is a challenge, although VEGF, FGF, and Ang separately have been safely used in short term clinical trials involving cardiac insufficiency and intermittent claudication $[13,17,101,102]$. In animal models of hind limb ischemia, Asahara et al. found a synergistic effect between VEGF and FGF [103]. However, treatment with a single 'primary' AG factor might suffice if all the other sequentially involved factors were endogenously available. Michael Simons speculated, "All that needs be done is to initiate the process of vascular growth, and nature will take its course" [13]. This may have been the unstated rationale for administering a single AG factor in the clinical trials mentioned above.

These clinical trials tested VEGF or FGF by injecting bolus amounts for short intervals directly to the affected area (heart, legs) or by administering them systemically for limited periods $[104,105]$. The absence of long term benefits in these studies may reflect these brief courses of treatment. The lesser ailments of old age may require daily therapy, much like treating a hormonal deficiency, such as hypothyroidism. Elsewhere I have discussed the 
advantage of administering recombinant AG factor in nasal drops, sprays, or nicotine-free snuff $[2,106]$.

\section{Summary}

Barring a fatal accident (trauma, poisoning) or an early terminal illness (cancer, stroke, etc.), long-lived persons will likely experience the lesser ailments of old age before developing serious cognitive problems and finally dying of pneumonia, cardiac failure, etc. In 1994, Daniel A. Drachman considered a later threat to the elderly in an article entitled, "If we live long enough, will we all be demented?" [107]. Theoretically, a further reduction in the cerebral CD would lead to this condition in the very aged.

Finally, this essay proposes that as people (and animals) age, angiogenesis wanes throughout the body and the microcirculation declines in most or all organ systems. Old age is viewed here in part as an age-linked deficiency state of angiogenic growth factors. In elderly people the lesser ailments generally appear first, while more serious cognitive problems may follow from a further decline or imbalance of these factors. Various organ systems decline in function or fail in time -- hormonal, renal, cardiac, etc. Regular administration of low levels of selected recombinant angiogenic factors seems a tenable treatment to consider for the above hallmarks of aging. 


\section{The Role of Capillaries in the Lesser Ailments of Old Age \\ (muscle weakness, minor memory lapses, \& cold intolerance) \\ and in Alzheimer's Disease \& Vascular Dementia: \\ the Potential of Pro-Therapeutic Angiogenesis}

\section{Acknowledgements ....}

I gratefully acknowledge the invaluable assistance of Mrs. Amanda Williams, Medical Center Library, University of Kentucky and the continued support of I.S. Tray II.

\section{References}

1. Ambrose CT (2012) Neuroangiogenesis: a Vascular Basis for Alzheimer's disease and cognitive decline during aging. J Alzheimer's Disease 32: 773-388.

2. Ambrose CT (2015A) A Therapeutic Approach for Senile Dementias: Neuroangiogenesis. J Alzheimer's Disease 43: 1-17.

3. de la Torre JC, Mussivand T (1993) Can disturbed brain microcirculation cause Alzheimer's disease? Neurolog Res 15, 146-153.

4. Kalaria RN, Hedera H (1995) Differential degeneration of the cerebral microvasculature in Alzheimer's dis. Neuro Report 6, 477-480.

5. Buée I, Hof PR, Delacourte A (1997) Brain Microvascular Changes in Alzheimer's Diseases and Other Dementias. Ann NY Acad Sci 826, 7-24.

6. Esiri MM (2000) Which Vascular Lesions Are of Importance in Vascular Dementia? Ann 
NY Acad Sci 903, 239-243.

7. Farkas E, Luiten PGM (2001) Cerebral microvascular pathology in aging and Alzheimer's disease. Prog Neurobiology 64: 575-611.

8. Grammas P, Yamada M, Zlokovic B (2002) The cerebromicrovasculature: A key player in the pathogeneis of Alzheimer's disease. J Alzheimer's Dis 4, 217-223.

9. Zlokovic BV (2005) Neurovascular mechanisms of Alzheimer's neurodegeneration.

Neurosciences 28: 202-208.

10. Craigie EH (1925) Postnatal changes in vascularity in the cerebral cortex of the male albino rat. J Comp Neurol 39: 301-324.

11. Riddle DR, Sonntag WE, Lichtenwalner RJ (2003) Microvascular plasticity in aaging. Ageing Res Review 2: 149-168.

12. Brown WR, Thore CR (2011) Review: Cerebral microvacular pathology in ageing and neurodegeneration. Neuropath Applied Neurobiol 37: 56-74.

13. Simons M (2005) Angiogenesis. Where Do We Stand Now? Circulation 111: 1556-1566.

14. Risau W (1997) Mechanisms of angiogenesis. Nature 386: 671-674.

15. Ambrose CT (2015) Muscle weakness during aging: a deficiency state involving declining angiogenesis. Ageing Res Rev 23: 139-153.

16. Edelberg JM, Reed MJ (2003) Aging and Angiogenesis. Frontiers Biosci 81: 1199-1209.

17. Klagsbrun M, D’Amore PA (1991) Regulators of Angiogenesis. Annu Rev Physiol. 53: 217-239.

18. Reich ES (2010) Self-plagiarism case prompts calls for agencies to tighten rules. Nature 468: 745 .

19. Frontera WR, Hughes VA et al. (2000) Aging of skeletal muscle: a 12-yr longitudinal 
study. J Appl Physiology 88: 1321-1326.

20. Degens H, Korhonen MT (2012) Factors contributing to the variability in muscle ageing. Maturitas 73: 197-201.

21. Coggan AR, Spina RJ et al. (1992) Histochemical and enzymatic comparison of the gastrocnemius muscle of young and elderly men and women. J Gerontology: Biolog Sci 47: B71-76.

22. Proctor DN, Sinning WE et al. (1995) Oxidative capacity of human muscle fiber types: effects of age and training status. J Appl Physiol 78: 2033-2038.

23. Chilibeck PD, Weiss JJ et al. (1997) Muscle capillarization, $\mathrm{O}_{2}$ diffusion distance, and $\mathrm{VO}_{2}$ kinetics in old and young individuals. J Appl Physiol 82, 63-69.

24. Ryan NA, Zwetsloot KA (2006) Lower skeletal muscle capillarization and VEGF expression in aged vs. young men. J Appl Physiol 100: 178-185.

25. Haidet GC, Parsons D (1991) Reduced exercise capacity in senescent beagles: an evaluation of the periphery. Am J Physiol 260: H173-H182.

26. Degens H, Veerkamp JH et al. (1993) Capillarization and fibre types in hypertrophied plantaris in rats of various ages. Resp Physiol 94, 217-226.

27. Leosco D, Rengo G et al (2007) Prior exercise improves age-dependent vascular endothelial growth factor downregulation and angiogenesis responses to hind-limb ischemia in old rats. J Gerontology: Biolog Sci 62A: 471-480.

28. Rivard A, Fabare J-E et al. (1999) Age-dependent impairment of angiogenesis. Circulation 99: 111-120. (Figs. 5G, 5H)

29. Drubaix I, Giakouarnakis A et al. (1998) Preliminary data on the age-dependent decrease in basic fibroblast growth factor and platelet-derived growth factor in the human vein wall and 
in their influence on cell proliferation. Gerontology 44: 9-14.

30. Solerte SB, Fioravantil M (2002) Downregulation of vascular endothelial growth factor generation from immune cells in Alzheimer's disease. Neurobiology Aging 23 (suppl 1): S532.

31. Croley AN, Zwetsloot KA, Westerkamp LM et al (2005) Lower capillarization, VEGF protein, and VEGF mRNA response to acute exercise in the vastus lateralis muscle of aged vs. young women. J Appl Physiol 99: 1872-1879.

32. Swift ME, Kleinman HK, DiPietro A (1999) Impaired wound repair and delayed angiogenesis in aged mice. Lab Invest 79: 1479-148.

33. Wagatsuma A (2006) Effect of aging on expression of angiogenesis-related factors in mouse skeletal muscle. Expl Gerontology 41: 49-54.

34. Adolfsson J, Ljungqvist A., Tornling G, Unge G (1981) Capillary increase in the skeletal muscle of trained young and adult rats. J Physiol 310: 529-532.

35. Gavin TP, Ruster, RS et al. (2007) No difference in the skeletal muscle angiogenic response to aerobic exercise training between young and aged men. J Physiol 58.5: 231-239

36. Schacter DL. (2001) How the Mind Forgets and Remembers. The Seven Sins of Memory. Boston: Houghton Mifflin.

37. Carey B (2014) Thinking slows mind? Not so fast. Int'l Herald Tribune 29 January 2014, p. 7.

38. McGaugh JL (2013) Making lasting memories: Remembering the significant. Proc Na Acad Sci 110: 10402-10407.

39. Kuschinsky W, Paulson OB (1992) Capillary Circulation in the Brain. Cerebrovascular. 
Brain Metab Rev 4: 261-286.

40. Collins RC, Wagman IL, Lymer L, Matter JM (1987) Distribution and recruitment of capillaries in rat brain. J Cereb Blood Flow Metab 7 (suppl 1): S336.

41. Kikano GE, LaManna JC, Harik SI (1989) Brain perfusion in acute and chronic hyperglycemia in rats. Stroke 20: 1027-1031.

42. Weiss HR (1988) Measurement of cerebral capillary perfusion with a fluorescent label. Microvasc Res 36: 172-180.

43. Allen JS, Bruss J, Damasio H (2005) The aging brain. The cognitive reserve hypothesis and hominid evolution. Am J Hum Biol 17: 673-689.

44. Goldman H, Berman RF, Gershon S, Murphy SL, Altman HJ (1987) Correlation of Behavioral and Cerebrovascular Functions in the Aging Rat. Neurobiol Aging 8: 409-416.

45. Desjardins M, Berti R, Lefebvre J, Dubeau S, Lesage F (2014) Aging-related differences in cerebral capillary blood flow in anesthetized rats. Neurobiol Aging 35: 1947-1955.

46. Mann DM, Eaves NR et al. (1986) Quantitative changes in cerebral cortical microvasculature in ageing and dementia. Neurobiol Ageing 7: 321-330. (Table 7)

47. Fischer VW, Siddiqi A, Yusufaly Y (1990) Altered angioarchitecture in selected areas of brains with Alzheimer's disease. Acta Neuropath 79: 672-679. (Table 2)

48. Buchweitz-Milton E, Weiss H (1987) Perfused capillary morphology in the senescent brain. Neurobiology Aging 8: 271-276. (Tables 2 \& 4)

49. Viboolvorakul S, Patumraj S (2014) Exercise training could improve age-related changes in cerebral blood flow and capillary vascularity through the upregulation of VEGF and eNOS. Biomed Res Int'1 2014: Article ID 230791: 1-12. 
50. Borisov VV, Lin DC (2014) Temperature fluctuations in the lower limbs of young and elderly individuals during activities of daily living. Exper Gerontology 57: 243-249.

51. Guergova S, Dufour A (2011) Thermal sensitivity in the elderly: a review. Ageing Res Rev 10: 80-92.

52. Taylor NAS, Allsopp NK, Parkes DG (1995) Preferred Room Temperature of Young vs. Aged Males: the Influence of Thermal Sensation, Thermal Comfort, and Affect. J Gerontology 50A: M216-M221.

53. Rupnick MA, Panigrahy D, Zhang C-Y, Dallabrida SM, Lowell BB, Langer R, Folkman MJ (2002) Adipose tissue mass can be regulated through the vasculature. Proc Na Acad Sci 99: 10730--10735.

54. Gealekman O, Guseva N, Hartigan C, Apotheker S, Gorgoglione M, Gurav K, Tran K-V, et al. (2011) Depot Specific Differences and Insufficient Subcutaneous Adipose Tissue Angiogenesis in Human Obesity. Circulation 18: 186-194.

55. Silha JV, Krsek M, Sucharda P, Murphy LJ (2005) Angiogenic factors are elevated in overweight and obese individuals. Intl J Obesity 29: 1308-1314.

56. Helmbold P, Lautenschläger C, Marsch WC, Navak RC (2006) Detection of a Physiological Juvenile Phase and the Central Role of Pericytes in Human Dermal Microvascular Aging. J Invest Dermatol 126: 1419-1421.

57. Výbohová V, Mellová Y, Adamicová K, Adamcov M, Hešková G (2012) Quantitative changes of the capillary bed in aging human skin. Histol Histopathol 27: 961-967.

58. Vollmar B, Morgenthaler M, Amon M, Menger MD (2000) Skin microvascular adaptations during maturation and aging of hairless mice. Am J Physiol Heart Circ Physiol 279: H1591-H1599. 
59. Robbins J, Bridges AD, Taylor A (2006) Oral, pharyngeal and esophageal motor function in aging. GI Mortality online (2006) doi:10.1038/gimo39.

60. Russell JA, Nagai H, Connor NP (2008) Effect of Aging on Blood Flow in Rat Larynx. The Laryngoscope 118: 559-563.

61. Gabella G (2001) Development and ageing of intestinal musculature and nerves: the guinea-pig taenia coli. J Neurophysiol 30: 733-766.

62. Bailes B, Reeve K (2013) Constipation in older adults. The Nurse Practitioner 38: 2125.

63. Stefanska A, Eng D, Kaverina N, Duffield JS, Pippin JW, Rabinovitch P, Shankland SJ (2015) Interstitial pericyte decrease in aged mouse kidneys. AGING 7: 370-381.

64. Urbieta-Caceres VH, Syed FA, Lin J, Zhu X-Y, Jordan KL et al (2012) Age-dependent renal cortical microvascular loss in female mice. Am J Physiol Endocrinol Metab 301: E979-E986.

65. Kang D-H, Joly AH et al. (2001) Impaired Angiogenesis in the Aging Kidney: Vascular Endothelial Growth Factor and Thrombospondin-1 in Renal Disease. Am J Kidney Dis 37: 601-611.

66. Braga FJHN, Manco JC, Souza JF, Ferrioli E, De Andrade J, Iazigi N (1996) Agerelated reduction in ${ }^{99} \mathrm{Tc}^{\mathrm{m}}$-DTPA alveolar-capillary clearance in normal humans. Nuclear Medicine Commun 17: 971-974.

67. McGarth MW, Thomson ML (1959) The effect of age, body size and lung volume change on alveolar-capillary permeability and diffusing capacity in man. J Physiol 146: $572-582$.

68. Philipps GD, Stone AM, Schultz JC, Whitehead RA, Jones RB, Goodkin ML, Ruebel 
MW, Knighton DR (1995) Age-related alterations in the morphology of femoral artery vasa vasorum in the rat. Mechanisms of Aging and Development 82: 149-154.

69. Solerta SB, Fioravantil M (2002) Downregulation of vascular endothelial growth factor generation from immune cells in Alzheimer's disease. Neurobiology Aging 23 (suppl 1): S532.

70. McLean AJ (2003) Age-related pseudocapillarization of the human liver. J Path 200: 112-117.

71. Hilmer SN, Cogger VC, Fraser R, McLean AJ, Sullivan D, LeCouteur DG (2005) Agerelated changes in the hepatic sinusoidal endothelium impede lipoprotein transfer in the rat. Hepatology 42: 1349-1354.

72. Mitchell SJ, Huizer-Pajkos A, Cogger VC, McLachlan AJ, LeCoueur DG, Jones B, de Cabo R, Hilmer SN ( 2011) Age-related pseudocapillarization of the liver sinusoidal endothelium impairs the hepatic clearance of acetaminophen in rats. J Gerontol A Biol Sci Med Sci 66A: 400-408.

73. Ambrose CT (2016) Angiogenesis, Aging, and Alzheimer's Disease. American Scientist 104: 82-85.

74. Mortimer JA. (2012) The Nun Study: Risk Factors for Pathology and Clinical-Pathologic Correlations. Current Alzheimer Res 9: 1-7.

75. Wang, P, Xie Z-H, Guo Y-J, Zhao C-P, Jiang H, Song Y, Zhu Z-Y, Lai C, Xu S-L, Bi J-Z (2011) VEGF-induced angiogenesis ameliorates the memory impairment in APP transgenic mouse model of Alzheimer's disease. Biochem Biophys Com 411, 620-626.

76. Goldsmith HS (2014) Benefit of Omental Blood Flow in Alzheimer's Disease: Effect on Deteriorating Neurons. JK Alzheimer's Dis 42: S277-S280. 
77. Marx JL (1974) Aging research (I): cellular theories of senescence. Science 186: 11051107.

78. Hall GS (1922) Senescence: the Last Half of Life. New York: D. Appleton.

79. Bjorksten J (1962) Aging: present status of our chemical knowledge. J Am Geriatric Soc 10: $125-139$.

80. Comfort A (1974) The position of aging studies. Mechanisms Ageing \& Devel 3: 1-31.

81. Hayflick L (1975) Current theories of biological Aging. Fed Proc 34: 9-13.

82. Weinert BT, Timiras PS (2003) Physiology of Aging. J App. Physiol 95: 1706-1716.

83. Duc HT (2014) The biological time calendar. Biomed Aging Path 4: 77-89.

84. Raschetti R, Albanese E et al (2007) Choline inhibitors in mild cognitive impairment: a systematic review of randomized trials. PLOS Medicine 4(11): e338.

85. Kaduszkiewicz H, Zimmermann T et al. (2005) Cholinesterase inhibitor for patients with Alzheimer's disease: systematic review of randomised clinical trials. Brit Med J 331: 321328.

86. Kavirajan H, Schneider LS (2007) Efficacy and adverse effects of cholinesterase inhibitors and memantine in vascular dementia: a meta-analysis of randomized controlled trials. Lancet Neurology 6: 782-792.

87. Román GC, Kalaria RN (2006) Vascular determinants of cholinergic deficits in Alzheimer disease and vascular dementia. Neurobiol Rev 7: 1769-1785.

88. Mecocci P, Polidori MC (2012) Antioxidant clinical trials in mild cognitive impairment and Alzheimer's disease. Biochim Biophys Acta 1822: 631-638.

89. Lamberts SWJ, van den Beld A, van der Lely A-J (1997) The Endocrinology of Aging. Science 278: 419-424. 
90. Lecce L, Lam YT, Lindsay LA, Yuen SC, Simpson PJL, Handelsman DJ, Ng MKC (2014) Aging impairs VEGF-medicate androgen-dependent regulation of angiogenesis. Mol Endocrinol 218: 1487-1501.

91. Ferrara N, Kerbel RS. (2005) Angiogenesis as a therapeutic target. Nature 438: 967-974.

92. Carmeliet P, Jain RK (2011) Molecular mechanisms and clinical applications of angiogenesis. Nature 473, 298-307.

93. Issa R, Krumpski J et al (1999) Vascular endothelial factor and its receptor, KDR, in human brain tissue after ischemia stroke. Lab Invest 79: 417-425.

94. Ward N, LaManna JC (2004) The neurovascular unit and its growth factors: coordinated response in the vascular and nervous systems. Neurological Res 26: 870-883.

95. Wang Y, Galvan V et al. (2006) Vascular endothelial growth factor improves recovery of sensorimotor and cognitive deficits after focal cerebral ischemia in the rat. Brain Res 1115: 186-193.

96. Baloyannis SJ (2015) Brain capillaries in Alzheimer's disease. Hell J Nucl Med 18 (Suppl 1): 152.

97. Heinl-Green A, Radke PW, Munkonge FM, Frass O, Zhu J, Vincent K et al. (2005) The efficacy of a 'master switch gene' HIF-1 $\alpha$ in a porcine model of chronic myocardial ischaemia. Europ Heart J 26: 1327-1332.

98. Clinical Trials.gov. (2015) Safety and Efficacy Study of Ad2/Hypoxia Inducible Factor (HIF)-1 $\alpha /$ VP16 Gene Transfer in Patients with Intermittent Claudication (WALK). https://clinical trials.gov/ct2/show/NCT00117650.

99. Semenza GL (2010) Defining the role of hypoxia-inducible factor 1 in cancer biology and therapeutics. Oncogene 29: 625-634. 
100. Thomas GV, Tan C, Mellinghoff IK, Welsbie DS, Chan E, Fueger B, Czernin J, Sawyers CL (2006) Nature Med 12(1): 122-127.

101. Post MJ, Laham R, Sellke FW, Simons M (2001) Therapeutic angiogenesis in cardiology using protein formulations. Cardiovascular Res 49: 522-531.

102. Lederman RJ, Mendelsohn FO, Anderson RD et al (2002) Therapeutic angiogenesis with recombinant fibroblast growth factor-2 for intermittent claudication (the TRAFFIC study): a randomized trial. Lancet 359: 2053-2058.

103. Asahara T, Bauters C, Zheng LP, Takeshita S, Bunting S, Ferrara N, Symes JF, Isner JM (1995) Synergistic effect of vascular endothelial growth factor and basic fibroblast growth factor on angiogenesis in vivo. Circulation 92 (9 Supp;): 365-71.

104. Takashita S, Zheng LP et al (1994) Therapeutic angiogenesis. A single intraarterial bolus of vascular endothelial growth factor augments revascularization in a rabbit hind limb model. J Clin Invest 93: 662-670.

105. Simons M, Annex BH, Laham RJ, Kleiman N, Henry T, Dauerman H, Udelson JE et al. (2014) Pharmacological Treatment of Coronary Artery Disease with Recombinant Fibroblast Growth Factor-2. Double-Blind, Randomized, Controlled Clinical Trial. Circulation 105: 788-793.

106. Ambrose CT (2013) Alzheimer's Diseases: the Great Morbidity of the $21^{\text {st }}$ Century. American Sci 101: 194-201.

107. Drachman DA (1994) If we live long enough, will we all be demented? Neurology 44: 1563-1565. 
Table 1. MUSCLE

Muscle -- CD

-- Cogan [21]

-- male

-- female

-- Rivard [28]

-- rabbits

-- mice

\section{Muscle -- AG}

-- Ryan [24]

-- men ... VEGF protein

-- men ... mRNA VEGF

-- men exercise ... mRNA VEGF

-- Wagatsuma [33]

-- mice

\section{YOUNG}

308 (av. 24 y.)

338

170 (6-8 m.)

710 (12 w.)

$1.05(19-25$ y.)

1.0

3.4

1.0 (av. $2.5 \mathrm{~m}$.)

\section{OLD}

228 (av. 64 y.)

248 “

130 (4-5 y.)

350 (2 y.)
0.55 (60-72 у.)
0.4 “
1.8 “
0.7 (22 m.) 


\section{Table 2. BRAIN}

\section{Brain -- CD}

-- Mann [46]

-- people ... frontal cortex

-- Fisher [47] ... normal subjects vs. AD

-- pre-frontal cortex

-- basal forebrain

-- hippocampus

-- Buchweitz-Milton [48]

-- rats ... cortex

-- rats ... 6 brain areas

\section{Brain -- AG}

-- Viboolvorakul [49]

-- rats ... parietal cortex

\section{YOUNG}

966 (26-58 у.)

94.6 (23-90 у.)

86.8

82.3

830 (8-10 m.)

837

،

$32.3(4-6 \mathrm{~m}$.

\section{OLD (AD)}

784 (76-96 у.)

75.4 (AD, 76-92 у.)

42.7 "

50.2 “

577 (21-33 m.)

592 “ 
Table 3. SKIN \& OTHER SITES

SKIN -- CD

$\underline{\text { ADULT }} \quad \underline{\text { OLD }}$

-- Helmbold [56]

-- human

$4.4(15-20 \& 39-40$ yr.)

2.3 ( $>70$ yr.)

-- Vybohova [57]

-- human $\mathrm{CD}, \% /$ unit area

1.42 (31-50 yr.) $\quad \mathbf{0 . 4 7}$ (81-89 yr.)

-- Vollmer [58]

-- hairless rat ear, CD

77.6 (30 wk.)

37.5 (78 wk.)

LARYNX -- CD

-- Russell [60]

-- rat thyroarytenoid muscle

17.0 (9 mo.)

9.35 (28-30 mo.)

COLON -- CD

-- Gabella [61]

-- guinea pig ... taenia coli

(longitudinal muscles of colon)

$\mathbf{9}$ /unit area (n.d.) 5 /unit area (n.d.)

KIDNEY -- CD \& AG

-- Stefanska [63]

-- mouse kidney cortex, CD

-- mouse kidney medulla, CD

-- Urbieta-Caceres [64]

-- mouse renal cortex, CD

-- Kang [65]

-- rat kidney, peritubular, capillary staining

-- rat, kidney medulla, VEGF expression

1.40 (3 mo.)

1.52 "

30 (6 mo.)

$11.3 \%$ (3 mo.)

$39.3 \%$ “

$\mathbf{0 . 8 4}$ (18-36 yr.)

0.73 (38-57 yr.)
0.93 (27 mo.)

1.04 "

17 (18-22 mo.)

$5.4 \%$ (24 mo.)

$19.2 \%$ “

LUNG -- $\mathrm{D}_{\mathrm{CO} / \mathrm{VC}} \cong \mathrm{CD}$

-- McGrath [67]

-- human diffusion capacity for $\mathrm{CO}$, corrected (corrected for lung size, using $\mathrm{D}_{\mathrm{CO}} /$ vital capacity )

VASA VASORUM -- CD

-- Phillips [68] -- rat femoral artery .. compared with 2 mo. 'reduced' (12 mo.)

more reduced (24 mo.)

MONONUCLEAR CELLS -- AG

-- Solerte [69]

-- human, VEGF

296 (av. 32.2 yr.)

137 (av. 77 yr.)

125 (AD, av. 76.5 yr.) 
** For the sake of simplicity, margins of error and units of measurement are omitted here. Only the senior author of papers is cited. ... m. $=$ months $\ldots \mathrm{y}$. $=$ years $\ldots \mathrm{AD}=$ Alzheimer's disease n.d. $=$ not defined 
Table 4. Causes of Aging ... reviews [60-65]

A. Stochastic (random, chance) / organismal / function systemic / environmental

-- cumulative diseases: cancer, diabetes, hypertension, stroke, etc.

-- infectious diseases

-- chronic, low grade inflammation

-- accumulated environmental toxins (Clinker Theory)

-- intestinal toxins (Eli Metchnikoff)

-- defective clearance of effete cells and internal products

-- defective protein synthesis (1963 Orgel's Error Hypothesis)

-- chemical cross linking

-- general stress ... wear \& tear (Hans Selye)

-- oxidative damage ... free radical toxicity

-- radiation ... chromosomal breaks

-- defective DNA repair

-- epigenetic modification

B. Developmental-genetic / molecular-cellular / intrinsic / endogenous / programmed

-- biological clock ... longevity gene

-- cellular senescence ... programmed cell death ... apoptosis

-- telomere shortening 
-- loss of stem cell renewal

-- somatic mutations ... genetic instability ... defective DNA, RNA, proteins

-- defective transcription ... (Codon Restriction Theory)

-- dysfunctional mitochondria

-- defective autosomal-lysosomal system

-- reduced autophagy efficiency ... defective cellular clearance

-- altered immune system ... impaired immune surveillance (thymic atrophy)

-- altered histo-incompatibility ... increasing autoimmunity

-- neuroendocrine deficiency ... waning hormones \& receptors

-- age-associated declining angiogenic factors ... Angiogenesis Hypothesis 